\title{
Erratum to: A molecular phylogenetic framework for Bacillus subtilis using genome sequences and its application to Bacillus subtilis subspecies stecoris strain D7XPN1, an isolate from a commercial food-waste degrading bioreactor
}

\author{
Joseph Adelskov ${ }^{1} \cdot$ Bharat K. C. Patel ${ }^{1}$ (i)
}

Published online: 8 June 2017

(c) Springer-Verlag Berlin Heidelberg 2017

Erratum to: 3 Biotech (2016) 6:96

DOI 10.1007/s13205-016-0408-8

In the online published article, the Bacillus subtilis subsp. stecoris name was wrongly published and it should be corrected to Bacillus subtilis subsp. stercoris throughout the manuscript.

Description of Bacillus subtilis subsp. stercoris subsp.

nov

Bacillus subtilis subsp. stercoris [ster'co.ris. L. gen. n. stercoris, of compost, from which the strain was isolated]. Grows optimally at $45^{\circ} \mathrm{C}$ (range 24-50), pH of 7 (range $5-9$ ), and grew in the presence of $7 \% \mathrm{NaCl}$. Facultative anaerobe by fermentation, forms white irregular colonies 1-2 $\mathrm{mm}$ in diameter when grown on dTSA, cells are straight rods $4-5 \mu \mathrm{m}$ length by $1 \mu \mathrm{m}$ width, and stain Gram positive. Degrades potato starch by amylase activity and expresses partial $\beta$-xylanase activity detected when grown on dTSA with $\mathrm{x}-\beta$-D-xyloside. Type strain is D7XPN1 ${ }^{\mathrm{T}}$ $\left(=\right.$ KCTC $\left.33554^{\mathrm{T}}, \mathrm{JCM} 30051^{\mathrm{T}}\right)$.

The online version of the original article can be found under doi:10.1007/s13205-016-0408-8.

Bharat K. C. Patel

bharat.patel@qut.edu.au

1 School of Earth, Environmental and Biological Sciences, Queensland University of Technology, Gardens Point, Brisbane, QLD 4001, Australia 